\title{
Design of a Freeze-Thaw System for Laboratory Soil Testing
}

\author{
Maha H. Nsaif ${ }^{1,2}$, Charles Heron ${ }^{1}$, Alec M. Marshall ${ }^{1}$ \\ ${ }^{1}$ University of Nottingham \\ Nottingham, U.K. \\ Maha.Nsaif@nottingham.ac.uk; Charles.Heron@nottingham.ac.uk; Alec.Marshall@nottingham.ac.uk \\ ${ }^{2}$ University of Technology \\ Baghdad, Iraq
}

\begin{abstract}
Freeze-thaw cycling is an important phenomenon in many areas in the world as it can affect the physical and mechanical properties of soil which can subsequently impact on above-ground structures and the stability of embankments. This paper describes the design of a laboratory testing system which is capable of applying freeze-thaw cycles to an element of soil and subsequently investigating the sample response to shearing. The system consists of a modified triaxial apparatus with the equipment able of reaching temperatures of $-9{ }^{\circ} \mathrm{C}$. This testing approach provides the functionality to apply confining and deviatoric stresses at the same time as subjecting the samples to freeze-thaw cycles thus replicating different conditions in the field.
\end{abstract}

Keywords: Freeze-thaw cycles, Soil mechanical properties, Triaxial system.

\section{Introduction}

In cold regions, geotechnical engineers face many challenges in designing structures which can be exposed to environmental conditions including permafrost degradation, icing, thaw settlement, slope failure and land slides. Many of these issues are related to phenomena such as frost heave and freeze-thaw cycles [1].

Freeze-thaw cycling is a weathering process which has a significant effect on the engineering properties of soils. These effects must be understood and modelled correctly when considering the stress-strain behavior of soil in the numerical analysis of boundary value problems [2].

To understand the behavior of soil under these conditions, representative laboratory tests are needed to investigate the behavior of soil. Although some systems for freezing have previously been commissioned [1], [3]-[7], the majority of these are intended to study frost heave rather than the effect of freeze-thaw cycles on the soil mechanical properties. This study introduces a freeze-thaw system capable of replicating different field stress scenarios (including isotopic compression and shear) and investigating the mechanical behavior of the soil following exposure to freeze-thaw cycles.

\section{Design Objectives}

The nature of the freezing environment including whether temperature variations propagate solely from the surface or from the horizontal direction also (one or three-dimensional freezing), rate of freezing and the magnitude of temperature fluctuations all need consideration in the design of the experimental apparatus. The aim of the design in this study is to have a three-dimensional cyclic freeze-thaw system with the ability to impose different stress conditions and subsequently to investigate the stress-strain behavior. The system must be able to control and maintain the soil sample temperature in addition to monitoring volume changes of the samples during the freeze-thaw process. Once the freeze-thaw cycles have been imposed, the system must be able to load the sample and monitor the deviatoric stress and strain response.

\section{System Components}

The system consists of two main components as shown in Figure 1. Firstly, a standard triaxial device is used to contain the sample, maintain a set stress condition during freeze-thaw cycling and to apply and monitor the response to the mechanical loading of the sample. The second component of the freeze-thaw system is the temperature control device - this consists of a reservoir of fluid contained within a freezer unit. Computer controlled pumps then circulate this fluid around a heat-transfer coil within the triaxial cell thus controlling the temperature of the cell fluid and therefore the soil sample. 
A standard cell configuration of $0.1 \mathrm{~m}$ diameter and $0.3 \mathrm{~m}$ length was used. The system has two advanced GDS digital pressure/volume controllers: one for the cell (confining) pressure and the other for back (sample pore) pressure (Figure 1f \& $1 \mathrm{~g}$ ). For applying a vertical load, a 50kN GDS loading frame was used and an external load cell with a maximum capacity of $5 \mathrm{kN}$ (figure 1a) was mounted on the frame. To cross-check the pore water pressure inside the sample, a pore pressure transducer was fitted to the base pedestal with a maximum range of $1 \mathrm{MPa}$. The system was controlled using the propriety GDSLAB software.

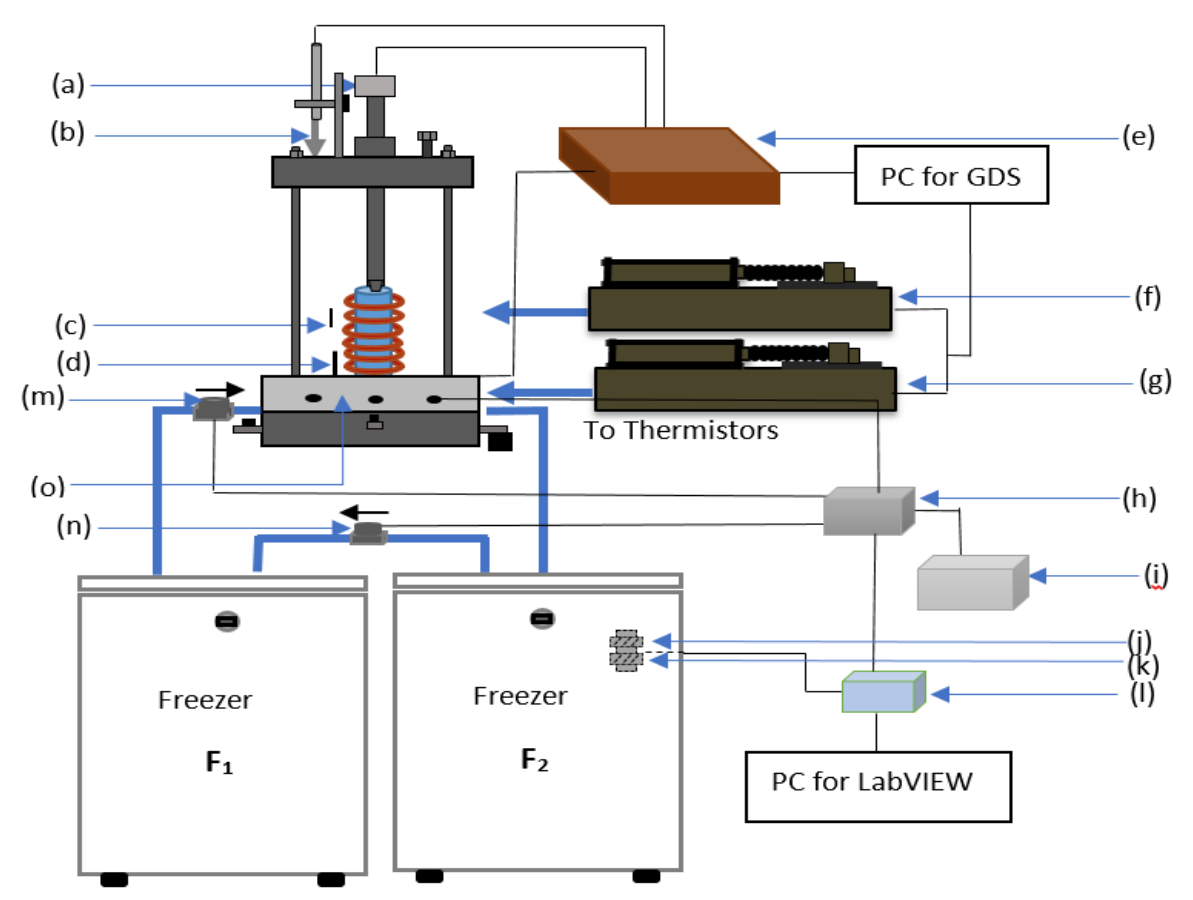

Fig. 1: Diagram of freeze-thaw system. (a) load cell, (b) LVDT, (c \& d) thermistors, (e) junction box, (f) cell controller, (g) back controller, (h) electronic box, (i) power supply, (j \& k) level Sensors, (l) data acquisition, (m \& n) pumps, (o) extension ring.

For the freeze-thaw system, it was required to develop and manufacture new components while maintaining all the standard triaxial functions. The freeze-thaw system works by passing a fluid, at a controlled temperature, through a coil of pipe placed within the triaxial cell. Copper pipe, with its high conductivity and durability, was chosen with an inner diameter of $6 \mathrm{~mm}$ and outer diameter of $6.4 \mathrm{~mm}$. Calculations were undertaken to determine the length of pipe required in order to control and maintain the temperatrure of the cell fluid given the losses. Consideration was given to the heat conduction between the triaxial cell and the wall of the cell, the heat transfer through the pipes and the heat conduction between the liquid inside the pipe and the wall of the pipe. The calculated length was $1.5 \mathrm{~m}$ which corresponded to a spiral with an external diameter of $65 \mathrm{~mm}$ and which consisted of 10 coils.

In order to connect the copper pipe to the external source of fluid, an extension ring was installed between the triaxial cell and pedestal (Figure 10). This also permitted the passage of the electrical connections for thermistors which were required within the cell to monitor the temperature. Two freezers were used to cool the fluid $\left(F_{1}\right.$ and $F_{2}$ in Figure 1). Both freezers had aluminium tanks placed within them to contain the coolant fluid. Ethylene glycol was used with a concentration of $50 \%$ as the coolant in this study as it remains in its liquid state until a temperature of $-50^{\circ} \mathrm{C}$. The same liquid was used in the cell and through the pipes around the sample. The soil sample however was saturated with de-aired water.

The electrical and electronic components of the system comprised of a temperature monitoring system, coolant liquid pumping system and a liquid tank level control system. Two thermistors were used to measure the temperature of the sample 
in the system. One was placed at the top of the sample and the other at the bottom. The instrumentation was monitored using an NI system and LabVIEW software provided the user interface. Two pumps (RS Pro Centrifugal Pump - 702-6882) are used in the system to transport the coolant (Figure $1 \mathrm{~m} \& 1 \mathrm{n})$. One is used to pump the liquid from one freezer $\left(\mathrm{F}_{1}\right)$ in Figure 1 through the triaxial cell to the second freezer $\left(\mathrm{F}_{2}\right)$ while the other is used to pump the liquid from the second freezer $\left(\mathrm{F}_{2}\right)$ to the first freezer $\left(\mathrm{F}_{1}\right)$, passing through the cell in the process. The pump flow rate can be controlled by regulating the voltage supplied. The liquid level in one tank was monitored using on/off level switches (Gems Sensors LS-3 Series) (Figure 1j \& $1 \mathrm{k}$ ). These are connected to the data acquisition system to report the full/empty status of the tank. A logical algorithm was implemented in the LabVIEW program to maintain the liquid levels in each tank by changing the flow rates. The traixial cell and connecting pipes (between freezers and cell) were insulated help maintain a steady sub-zero temperaitre witin the cell.

\section{Results and Discussion}

Following the assembly of the experimental apparatus, a preparatory commissioning test was conducted to illustrate the functionality of the system. The test was carried out with a dummy sample and an applied cell pressure of $100 \mathrm{kPa}$. The freezing stage was undertaken for 24 hours. Figure 2 shows the temperature changes which were recorded during the freezing stage from both thermistors. The temperature decreased to $-9^{\circ} \mathrm{C}$ and remained stable, which was sufficient for the requirements of the planned research. Figure (3) shows the recorded temperature changes during the thawing phase, which was done by simply disabling the pumps and allowing for natural temperature equalisation with the surrounding space $\left(21^{\circ} \mathrm{C}\right)$. The recorded temperatures on the upper and lower part of the sample moved in sync albeit with an offset with the upper thermistor showing a higher temperature as was expected given the natural convection which would occur within the cell. Furthermore, the system was successfully able to control the levels in the tanks automatically as monitored during the test which was run for approximately 48 hours.

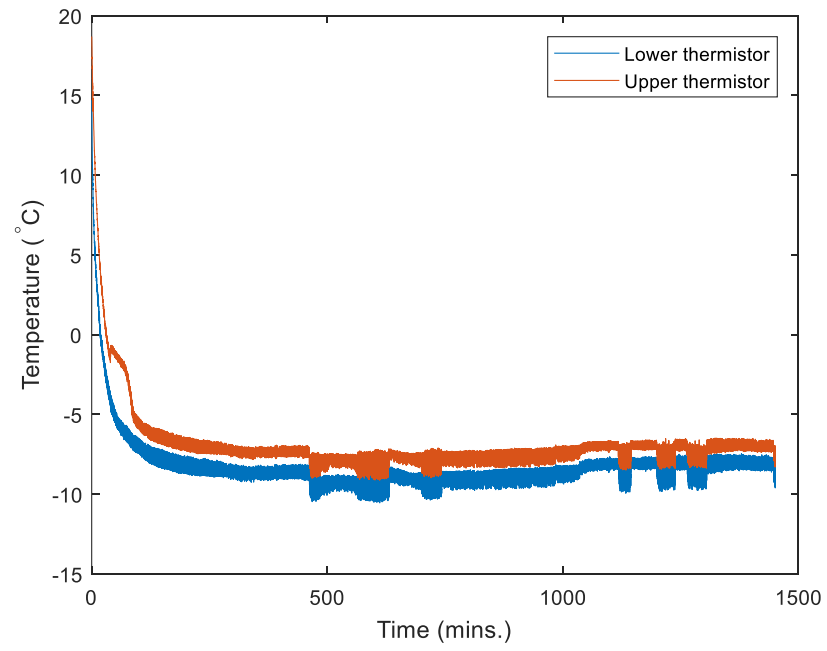

Fig. 2: Temperature changes which were recorded automatically by LabVIEW during freezing.

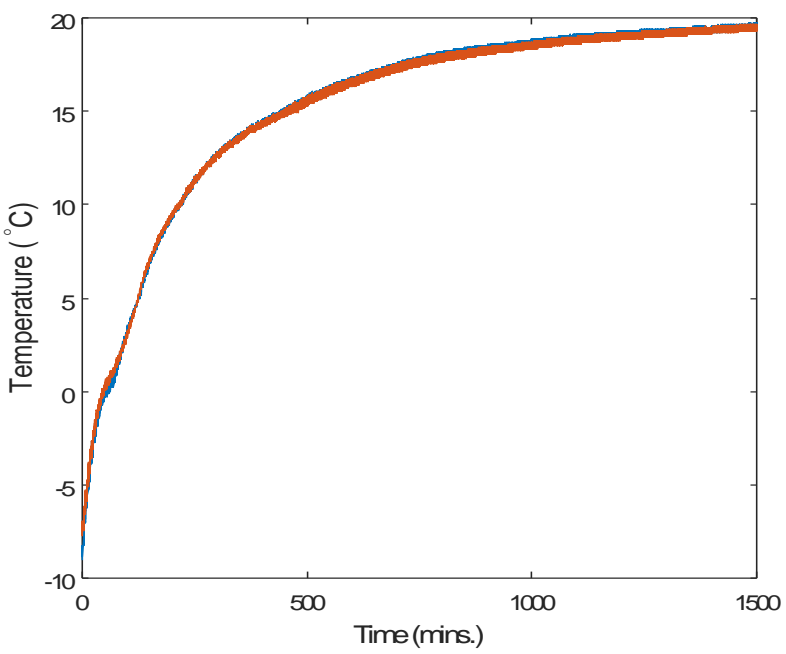

Fig. 3: Temperature changes which were recorded automatically by LabVIEW during thawing.

\section{Conclusions}

After the development and implementation of the freeze-thaw system, the designed system has successfully achieved the specified objectives. Advantages of the system include that the soil is frozen and thawed inside the cell, thus eliminating disturbance due to handling, and the system can reach and maintain a freezing temperature (around $-9^{\circ} \mathrm{C}$ ). Moreover, during freezing and thawing, continuous confining pressures can be applied representing different field conditions and a deviatoric stress can be applied during and/or after the cycles. The system will be used to apply different numbers of freeze-thaw cycles 
to the soil and investigate volume changes during freezing and thawing and the stress-strain behavior of the soil after exposure to the cycles.

\section{References}

[1] L. Zhang, W. Ma, C. Yang, and C. Yuan, "Investigation of the pore water pressures of coarse-grained sandy soil during open-system step-freezing and thawing tests," Eng. Geol., vol. 181, pp. 233-248, 2014.

[2] J. Qi, W. Ma, and C. Song, "Influence of freeze-thaw on engineering properties of a silty soil," Cold Reg. Sci. Technol., vol. 53, no. 3, pp. 397-404, 2008.

[3] P. Viklander, "Permeability and volume changes in till due to cyclic freeze / thaw," Can. Geotech. J., vol. 35, no. 3, pp. 471-477, 1998.

[4] E. Simonsen and U. Isacsson, "Soil behavior during freezing and thawing using variable and constant confining pressure triaxial tests," Can. Geotech. J., vol. 38, no. 4, pp. 863-875, 2001.

[5] Y. Lai, S. Li, J. Qi, Z. Gao, and X. Chang, "Strength distributions of warm frozen clay and its stochastic damage constitutive model," Cold Reg. Sci. Technol., vol. 53, no. 2, pp. 200-215, 2008.

[6] X. Yao, J. Qi, and W. Ma, "Influence of freeze-thaw on the stored free energy in soils," Cold Reg. Sci. Technol., vol. 56, no. 2-3, pp. 115-119, 2009.

[7] T. Ishikawa and S. Miura, "Infuence of freeze-thaw action on deformation-strength characteristic and particle crushability of volcanic coarse-grained soils," Soils Found., vol. 51, no. 5, pp. 785-799, 2011. 